\title{
“The Same Staff Can Be Enough”. Employers' Resilience Strategies in Recruitment Decisions*
}

\author{
Raimondo Ingrassia \\ Department of Economics, Business and Statistics, University of Palermo, Palermo, Italy \\ Email: raimondo.ingrassia@unipa.it
}

How to cite this paper: Ingrassia, R. (2018) "The Same Staff Can Be Enough". Employers' Resilience Strategies in Recruitment Decisions. American Journal of Industrial and Business Management, 8, 607-618.

https://doi.org/10.4236/ajibm.2018.83040

Received: February 27, 2018

Accepted: March 18, 2018

Published: March 21, 2018

Copyright $\odot 2018$ by author and Scientific Research Publishing Inc. This work is licensed under the Creative Commons Attribution International License (CC BY 4.0).

http://creativecommons.org/licenses/by/4.0/

\begin{abstract}
Studies on resilience have sprung from a need to understand the survival strategies of organizations when faced with the emergence of unexpected, potentially destructive and negative events in the lives of the organizations. This article, on the other hand, intends to highlight organizational resilience when confronted with unexpected positive events, seldom considered by such studies. This is the well-known macroeconomic phenomenon of the time lag between economic growth and labor demand at the moment that a regressive economic cycle is reversed. With which strategies do companies, in the face of such an event, transform a resilient attitude into real resilient behavior? Five strategies of organizational resilience are identified: Flexibility of working hours, staff re-allocation, minimization of turnover and absenteeism, job redesign, and reorganization of operations. A summary of results, managerial implications, contributions to studies and indications for future research conclude the article.
\end{abstract}

\section{Keywords}

Organizational Resilience, Unexpected Positive Events, Resilience Strategies of Employers, Recruitment

\section{Organizational Resilience: Definition and General Concepts}

Over the last few decades, the external environment of companies has become increasingly uncertain due to unpredictable events linked to market dynamics (changes in consumer behavior, competitors' actions, technological innovation, financial crises, trends in economic cycles, instability of public resources) and

*This article was presented at the XIX Workshop of the Italian Association of Business Organization (ASSIOA) on the theme: "The Resilient Organization: Design, Change and Innovation in the Globalized Economy", held in Rome on $15^{\text {th }}-16^{\text {th }}$ February 2018 at the l'Università Cattolica del Sacro Cuore. 
political, social and natural factors (terrorist acts, local conflicts, government instability, unclear public policies, natural disasters, etc.) [1] [2]. The ability to anticipate, adapt and react to such events has therefore become a fundamental organizational requisite for the survival of businesses in contemporary society. This ability has been defined with the term of resilience.

There is a very diverse list of definitions on this concept as the phenomenon of resilience is recognized not only in organizational and managerial sciences but also in other disciplines such as ecology, psychology, physical and chemical sciences, materials technologies, systems theory, etc. In very general terms, resilience means the ability of a system to absorb and respond specifically to uncertain and unpredictable events [3] [4] [5] [1].

Organizational studies have focused on resilient behaviors, identifying two different approaches for the analysis of the phenomenon Firstly, resilience is the ability of a system to react to new, unexpected, stressful, hostile or destabilizing crisis situations while maintaining its day-to-day functionality and performance. This view sees resilience as the ability of the organization to adapt to the reality that surrounds it without ruinous trauma to its existence. Its priorities are to avoid or limit the regressive dysfunctions and behaviors of the system through strategies to maintain performance and normal service. From this point of view, resilience would describe the adaptive-reactive or defensive properties of an organizational system. The second approach considers resilience as an ability to learn and develop new skills and enable the system to work by exploiting the opportunities that the unexpected event offers. This second view, which also presupposes reactive capacity, coincides with the capacity of the system to transform existing skills and acquire new ones. It would therefore describe the transformative-evolutionary or progressive properties of an organizational system [6]-[13].

\section{Properties of a Resilient Organizational System}

Organizational resilience, therefore, is the ability of a system to react to an unexpected event that threatens its survival by maintaining or transforming its usual functions. An organization that faces unforeseen events (aggressive acts of a competitor, damage to production plants, an unexpected drop in demand) finds itself in the situation of having to take unplanned organizational decisions regarding these unexpected developments.

The characteristics of a resilient organizational system were initially identified by a series of concentrated studies, not so much on the specific issues of resilience, but on the more general attitude of a system operating in a dynamic and complex environment [10]. According to these studies such a system must be; 1) flexible, in other words having the ability to change one's organizational structure quickly and at low cost; 2) agile, that is having the ability to think and promptly implement competitive responses; 3 ) adaptable, which is having the ability to reestablish a sense of harmony with the external environment. 
Subsequently, organizational studies have identified the typical characteristics of a resilient system based on four benchmarks [12] [14] [15] [16] [17]. 1) Robustness, intended as the will and drive to continue to conduct programmed operations. Examples of robustness are persevering in actions undertaken and maintaining position. 2) Redundancy, in other words the ability to create alternate resources as backup, and slack resources. Examples of redundancy are the interchangeability of personnel, the over-staffing of units and putting organizational resources in reserve. 3) Resourcefulness, understood as the ability to undertake autonomous initiatives and to develop information and plans in order to deal with discontinuities and to minimize the damage of the unforeseen event. Examples of resourcefulness are having a decision support system, adopting contingency plans, and having alternative action plans. 4) Rapidity, that is, the ability to act promptly to restore the workings of the system and to carry the action out. Examples of rapidity are the simplification of decisionmaking procedures and the timeliness of decisions.

Organizational studies have also looked at the relationship between resilience and Strategic Human Resource Management (SHRM), clarifying what the policies and procedures for personnel should be to support the resilience of an organizational system [10]. From the perspective of SHRM, organizational resilience is a mix of capability, routine, practices and processes concerning people and structures which involve three interrelated levels: cognitive, behavioral and contextual [7] [18]. Creating cognitive resilience means developing skills, practical sense and a capacity for problem solving. On a behavioral level it means developing the ability to conceive unconventional projects, to deviate from routine, to take preventive action. On a contextual level, it is having the ability to develop interpersonal relationships and form alliances in order to share information, knowledge, power and responsibility and obtain resources quickly. Staff policies at the cognitive level are, for example, ensuring a climate of trust in the workplace, promoting cross-functional empathy and using diversified recruiting services. Personnel policies consistent with behavioral resilience should encourage listening to employees, cross-functional cooperation and ample and flexible job descriptions. Finally, personnel policies that support the contextual dimension should be oriented towards fostering relationships and alliances with stakeholders, promoting empowerment in the workforce, evaluating actions based on the results obtained, and making information accessible. The ability of a system to operate in a dynamic and complex environment and the organizational resilience and personnel policies that result from it together constitute a nucleus of systematic attributes to evaluate cases and actual behaviors of resilience.

\section{The Unexpected Positive Event: Demand Recovery}

The research method follows a phenomenological approach in the study of the observed facts. Starting from a known occurrence we proceeded to a subjective 
interpretation that attributes form and meaning to the facts in terms of organizational resilience [19]. The research method followed in this study is therefore based on the organizational interpretation of a widely documented phenomenon in economic studies.

The survival of an organization is not only threatened by negative events, as the theory of resilience has accustomed us to thinking, but also by the inability of a system to seize favorable opportunities because they are unexpected or misunderstood. The unexpected positive event which is referred to is due to the well-known macroeconomic phenomenon of the time lag between economic growth and labor demand when a regressive economic cycle is reversed [20] [21] [22].

Despite the recovery of the Gross Domestic Product (GDP), companies do not believe that market demand can increase. There are many reasons to explain this attitude. Even when they receive new production orders, companies have little confidence in a recovery as they attribute it to the result of occasional circumstances that can be resolved via the use of inventories [23]. With particular reference to the Italian case, ISTAT documents a cyclical pattern in vacancies with respect to the industrial production index ${ }^{1}[24]$.

During the cyclical upswing that began around mid-2005, the increase in vacancies took effect with some delay. Symmetrically, in the slowdown phase of the 2007/2008 expansion there was a moderate decline. In other words, companies tend to adjust their workforce with some delay both in the case of expansion and in the case of recession in the economy. The surveys which reveal the Business Confidence Indicator (BCI) in the European Union report that the shortage of labor force is considered one of the major obstacle factors during the expansion phases of the economic cycle [23]. In these cases, companies tend to make use of existing, more experienced and trained personnel, until they have certainty of recovery.

There is, therefore, a tendency to hold back for a few quarters ( 2 - 4 quarters) before making adjustments, until a time in which the economic cycle has stabilized, perceptions of economic expansion have materialized and there is a more general optimism amog entrepreneurs an managers. During this period, companies do not hire staff and the aggregate unemployment rate tends to remain stationary. There are many studies, statistics and indicators that document this phenomenon [25]-[30].

Labor market rigidity generates adaption costs for which the "employers" decisions on whether to hire or fire are often postponed and are only acted upon once economic developments become so clear that they eventually have to take a decision. Hence, despite the fact that business opinion surveys may indicate a significant change in employment expectations, it may be several months before employers follow their feelings, once further confirmation of the economic situation has been provided. As a result, growth rates for the index of employment

${ }^{1}$ In the European Statistical System, vacancies are those job positions for which companies are looking for personnel. Therefore, vacancies can be considered an indicator of the hiring intentions of companies. 
could lag employment expectations by several months" [31].

The time lag between economic growth and an increase in employment has risen in recent decades, particularly in Europe [32]. Employment elasticity, which indicates how much employment increases for each percentage point of GDP growth (measured by the ratio between the rate of change in employment and GDP), was $14 \%$ in Italy in the period 1963-1979 which then dropped to $8.7 \%$ in the subsequent period 1980-2000. Over the following years employment elasticity started to grow again compared to the previous decades but it was not so much because of standard employment (full-time and permanent contracts) but rather due to the possibility of exploiting the secondary labor market to the full which allowed enterprises to take advantage of the opportunities offered by the use of part-time and other flexible forms of contract [32]. When the economic cycle positively evolves, companies, for a certain period of time, avoid increasing the workforce, tending to use the same resource base until they have certainty and knowledge of market demand. In other words, companies facing a positive event, of which they have little and uncertain information, prove to be rather resilient towards it.

The Excelsior survey conducted on a sample of a hundred thousand Italian companies, offers us some explanations for this phenomenon. The survey, carried out when there was a presumed reversal of Italy's negative economic cycle (end of 2014), focused on the factors that drive or hinder companies from hiring personnel [33]. When companies have little confidence in the recovery of the economic cycle, the reasons for hiring are dictated by: 1) the need for staff replacement of unavailable employees (due to leave, retirements, layoffs, absenteeism); 2) temporary adjustment of the workforce for occasional activities or seasonal work, 3) insourcing for previously outsourced work; 4) re-employment of workers temporarily excluded from the production process (CIG and GIGS). As far as hindrances are concerned, almost $81 \%$ of companies stated that they would not have taken on more staff anyway, despite the relatively optimistic growth forecasts, justifying their stance with the following reasons: a) adequate personnel (in $77.2 \%$ of cases); b) uncertain or falling demand (13.7\%); c) awaiting new contracts (6.8\%). It is due to a conservative, wait-and-see approach, a lack of confidence in the future and an inclination to maintain the existing staff (or, more often than not, to delay the readjustment) whether it is a case of pushing for or holding back on recruitment.

The question we ask ourselves is how companies translate a resilient attitude towards unexpected events which are positive for their development prospects, into real resilient behavior. In the following pages some explanations for this phenomenon are provided.

\section{4. “The Same Staff Can Be Enough". Employers' Resilience Strategies in Recruitment Decisions}

There is uncertainty within companies regarding the economic cycle and thus 
they perceive the first positive signs as temporary and ephemeral increases in demand. The employer reserves the right to expand company employment believing that the costs of adapting the workforce for the very short term exceed the costs of exploiting the existing organizational slack [21] [34] [35] [36]. The company tries to tackle the necessary production increases with the same workforce. Resilience strategies are aimed at optimizing the internal labor market with the constraint of the invariance of the workforce. The tools for implementing such strategies are discussed below. Each of them has different organizational resilience properties.

Working time flexibility strategies. Italian law allows companies to resort to forms of flexible organization regarding working time in cases of exceptional increases in production, impediments to new hiring and special events (exhibitions, fairs, etc.) (Legislative Decree 66/2003). Applying flexible work schedules, widely practiced in first and second collective bargaining, create an increase in overtime, daily and weekly fluctuations in work hours, staff management which focuses on crediting and debiting work hours, a concentrated week and conversion of part-time contracts into full time, as well as a need for night work and the rationalization of the work rota [37].

Such strategies require a general flexibility, agility and adaptability which allows working time to be shaped by the new production needs of the system for a short period of time. From the perspective of the theory of organizational resilience, these types of interventions require redundancy, resourcefulness and rapidity. Redundancy as changes to normal working hours increase the availability of unused standby hours. Resourcefulness as bargaining over working hours requires the ability to propose to the trade union counterparts innovative organizational solutions. Rapidity as many of these interventions need to be implemented in a very short time. Personnel policies with reference to company management's expectations are oriented towards pragmatism, managerial initiative and the ability to undertake cooperative actions with trade unions.

Staff re-allocation strategies. This regards staff mobility within the internal labor market. An increase in business may require a shift of resources from overstaffed areas of the company to sectors or production lines that have peaks in demand and increases in activity. Examples of staff re-allocation with a view to optimization and coordination of resources are observed in italian legislation, in corporate groups (Legislative Decree 276/2003, Article 30), in network contracts (Law 33/2009) and in public administrations (Legislative Decree 165/2001, Article 30). The organizational mechanism used is that of the secondment of employees. an employer is authorized to temporarily place one or more workers at the disposal of another employer. The employers involved can be group or network companies or other public administrations. Other examples of secondment are found in companies divided into divisions, such as banks or post offices, where employees are "loaned out" from one branch to another in order to face busy periods or large numbers of visitors. When using redundancy 
in other parts of the system, agility and rapidity of action are the most important aspects in reallocation strategies. Personnel policies with respect to company management's role expectations are based on cross-functionality and governance of internal relations and extended to group, network or public system ones.

Minimization of turnover and absenteeism strategies. These are actions taken to contain the dangers of decreasing the availability of staff due to leave, dismissal and voluntary retirement, and absenteeism. In the first two cases, the employer can offer incentives to the worker or solutions to delay in the short term their leaving the workplace. One example is the deferment of annual leave. Italian jurisprudence recognizes the granting of holidays to the worker as an autonomous organizational power of the employer, which must be exercised taking into account the productive needs of the company as a priority (Supreme Court Judgment 9816/2008).

In the case of absenteeism, employers should intervene through incentives and disincentives, such as productivity bonuses based on presence in the workplace and stringent checks on the legitimacy of the days of absence. The flexibility of the system is achieved, in this case, mainly through its ability to scale back on the difficult to control situations, at least in the short term. Resilience is expressed through forms of resourcefulness and robustness meant as empathy in the proposals and authority of the controls. The personnel policies are mainly aimed at enhancing the capacity for prevention and problem solving skills of company management, which must put forward convincing solutions to people who wish to leave the workplace.

Work redesign strategies. These are implementations that affect the individual and collective organization of labor. Redesign strategies can be conducted through job modifications for the purpose of optimizing working time. Interventions on job tasks from this perspective are: 1) assigning additional tasks of the same level of complexity and responsibility to people during normal working hours in order to fill the unused working time (job enlargement); 2) assigning people additional tasks of minor (job de-enrichment) or greater (job enrichment) complexity and responsibility with the same previous objective ${ }^{2} ; 3$ ) implementing job rotation initiatives and the integration of tasks aimed at rationalizing interdependencies and enhancing the complementarity and productivity of the members involved (work group). Using similar strategies guarantees the system internal flexibility through job flexibility while in terms of resilience, the ability of the company management to intervene authoritatively on the micro-organization of the work demonstrates robustness in the system. In this case, personnel policies must rely on all three levels of resilience described: cognitive, behavioral and contextual. Cognitive, as the company management must have the ability to assess people in relation to the assigned ${ }^{2}$ The Jobs Act of the Renzi Government in Italy (Legislative Decree 81/2015, Article 3) has recently introduced the possibility of assigning to the worker tasks lower than those for which they were hired if the existing organizational set-ups have changed (for example, for the re-organization of production processes or work tasks), provided that the worker maintains the same qualifications and remuneration. 
tasks (recruitment), practical sense and prudence in assigning new tasks, bearing in mind that the new tasks result in an increase in workloads and potential stress to employees [38] [39] [40]. Behavioral, as such actions require an expansion of job descriptions, employee involvement (listening), organizational mobility (cross-functional group). Contextual, as it is necessary to develop good relations with internal and external stakeholders (employees and trade unions) and implement effective employee empowerment policies.

Process reorganization strategies. These are actions which affect specific areas of the organization's function. Reorganizing processes means eliminating unnecessary phases and activities, carrying out independent activities at the same time, simplifying administrative procedures, better coordination of the units and the phases of the process, intervening on the critical issues that arise in its initial phases [41] [42]. These actions must be carried out to ensure organizational flexibility, operational agility and adaptation to changing production needs. The ability of the processes to continue to perform the assigned functions (robustness), reengineering of the processes (resourcefulness) and the ability to obtain immediate results (rapidity) characterize, in a resilient sense, these intervention strategies. Personnel policies must promote: on a cognitive level, new skills, practical sense and problem solving skills; on a behavioral level, innovative organizational projects and the questioning of routines; on a contextual level, a strong involvement of employees, ample sharing of information and knowledge and widespread powers and responsibilities.

Auxiliary resilience strategies. Many of the resilience strategies outlined above may require support in terms of investing in technology and staff training. Within a framework of organizational strategies which requires constant resources and immediate management feedback, investments in technology and staff training can only be on a small-scale (new, easy to learn software, rationalization of the production layout, increases in production capacity with small adjustments to machines and plants, specific instructions to personnel rather than a broader general training). Only at a later date, when growth forecasts have consolidated in the management's perception, can investments in technology and training have a larger dimension and depth.

\section{Results, Managerial Implications, Contributions to Studies and Future Research}

Results, managerial implications, contributions to studies and proposals for future research are presented below in this final section.

Results. The time lag between economic growth and labor demand shows that companies have a series of strategies to deal with unexpected positive events such as recovery in market demand after a regressive economic cycle and an increase in production with the same amount of resources. For a limited period of time companies do not modify the existing organizational structures (personnel, technologies, organizational model) but proceed with small local adjustments 
that do not revolutionize their overall structure. It is therefore an adaptivereactive resilience, in other words defensive, rather than a transformativeevolutionary one, in other words progressive.

Managerial implications. Company managers, with regard to the properties of a resilient organizational system, can implement a diversified set of strategies to manage staff shortages in the face of growth in production volumes and greater market opportunities. In such a context, company management should be authoritative, empathic, proactive, pragmatic and enterprising.

These skills would allow management to seize opportunities and overcome institutional constraints that could increase or limit the resilience of the system (work laws, internal rules and regulations, etc.). They would also allow the establishing of relationships and alliances with the main stakeholders involved in organizational resilience strategies in order to acquire their involvement and consent (unions, staff, suppliers). Another managerial implication is that the system should have resources that exceed its normal needs (slack resources) in quantities that allow more room for maneuver in case of unforeseen events. A further managerial implication is that the described resilience strategies are not cost-free. Although the workforce remains unchanged, it may be necessary to incur additional labor costs for the remuneration of flexible hours or expenses for reorganization and control of the system.

Contributions to studies. Resilience studies are born from a need to understand the survival strategies of organizations when faced with the emergence of unexpected, potentially destructive, negative events in the life of an organization. This paper offers an original contribution as it highlights a case of organizational resilience to unexpected positive events, seldom considered by the studies. This study respects two fundamental research principles: the empirical controllability of results and the ability to explain new facts [43]. In fact, the organizational resilience strategies described provide a useful key to verify in the field how and why, in the face of an unexpected event, companies are able, with the same resources, to continue to perform their usual functions without incurring damage (loss of market opportunities, loss of turnover, lack of production).

Future research. Research on organizational resilience to unexpected positive events is rather scarce. This paper proposes a promising research path that could develop along two directions: 1) case studies of positive events that call for resilient behaviors in organizations; for example, studies that address cases of organizational resilience in the face of unexpected seasonal or occasional production increases or studies that address the problem of sudden queues at the branches of a public office, bank or post office; 2) research on specific resilient properties and behaviors when organizations are faced with events favorable to their existence. In this study we have shown properties and behaviors very similar to those found in the resilience strategies used in the face of negative events. It would be interesting to find out if specific strategies are implemented 
in case of positive events.

\section{Conclusion}

This study looks at organizational resilience in the face of an unexpected positive event: The recovery of market demand after a regressive economic cycle. Employers, however, have little confidence that the recovery in demand will stabilize in the long term, and are convinced that the existing staff are enough to cope with the ephemeral increases in production and put in place various strategies of short-term organizational resilience. These strategies require authority, empathy, activism, pragmatism and resourcefulness, the ability to forge alliances, organizational involvement, exploitation of excess resources, the capacity to withstand a limited increase in labor costs. The resilience strategies used by employers illustrated in this article should provide scholars with a research framework to verify, in this field, the resilient behaviors of companies in the situations described. This study opens up new research paths on resilience, research which is usually focused on the analysis of the impact of negative events.

\section{References}

[1] Linnenluecke, M. and Griffiths, A. (2010) Beyond Adaptation: Resilience for Business in Light of Climate Change and Weather Extremes. Business \& Society, 49, 477-511. https://doi.org/10.1177/0007650310368814

[2] Azusa, K. and Hiroyuki, Y. (2013) Organizational Resilience: An Investigation of Key Factors that Promote the Rapid Recovery of Organizations. Academic Journal of Interdisciplinary Studies, 2, 188-194. https://doi.org/10.5901/ajis.2013.v2n9p188

[3] O’Neal, M.R. (1999) Measuring Resilience. Paper presented at the Annual Meeting of the Mid-South, Educational Research Association (Point Clear, AL, November, 17th-19th), 1-18.

[4] Seville, E. (2008) Resilience: Great Concept but What Does it Mean? Paper Presented at the US Council on Competitiveness Workshop, Risk and Resilience. Wilmington (US), November 2008. 1-10.

http://scholar.google.com/scholar_lookup?title=+"Resilience:+Great+Concept+But +What+Does+It+Mean?"\&author=Seville+E.\&publication_year=2008

[5] McManus, S., Seville, E., Vargo, J. and Brunsdon, D. (2008) Facilitated Process for Improving Organizational Resilience. Natural Hazards Review, 9, 81-90. https://doi.org/10.1061/(ASCE)1527-6988(2008)9:2(81)

[6] Sutcliffe, K.M. and Vogus, T.J. (2003) Organizing for resilience. In: Cameron, K.S., Dutton, J.E. and Quinn, R.E., Eds., Positive Organizational Scholarship: Foundations of a New Discipline, Berrett-Koehler, San Francisco, 94-110.

[7] Lengnick-Hall, C.A. and Beck, T.E. (2005) Adaptive Fit versus Robust Transformation: How Organizations Respond to Environmental Change. Journal of Management, 31, 738-757. https://doi.org/10.1177/0149206305279367

[8] Jamrog, J.J., McCann, J.E.I., Lee, J.M., Morrison, C.L., Selsky, J.W. and Vickers, M. (2006) Agility and Resilience in the Face of Continuous Change. American Management Association.

[9] Ayling, J. (2009) Criminal Organizations and Resilience. International Journal of 
Law, Crime and Justice, 37, 182-196. https://doi.org/10.1016/j.ijlcj.2009.10.003

[10] Lengnick-Hall, C.A., Beck T.E. and Lengnick-Hall, M.L. (2011) Developing a Capacity for Organizational Resilience through Strategic Human Resource Management. Human Resource Management Review, 21, 243-255. https://doi.org/10.1016/j.hrmr.2010.07.001

[11] Zhang, R. and Liu, W. (2012) Organizational Resilience Perspective: Facilitating Organizational Adaptation Analysis. In: International Conference on Economics Marketing and Management, IACSIT Press, Singapore, 55-59.

[12] Teoh, S.Y. and Zadeh, H.S. (2013) Strategic Resilience Management Model: Complex Enterprise Systems Upgrade Implementation. Proceedings of the 17 th Pacific Asia Conference on Information Systems, Illinois, 18-22 July 2013, 1-12.

[13] Denyer, D. (2017) Organizational Resilience: A Summary of Academic Evidence, Business Insights and New Thinking. BSI and Cranfield School of Management. https://www.cranfield.ac.uk

[14] Bell, M. (2002) The Five Principles of Organizational Resilience. http://www.gartner.com/DisplayDocument?doc_cd=103658

[15] Tierney, K. (2003) Conceptualizing and Measuring Organizational and Community Resilience: Lessons from the Emergency Response Following the September 11, 2001 Attack on the World Trade Center. University of Delaware, Disaster Research Center, Newark.

[16] Jung, K. and Song, M. (2015) Linking Emergency Management Networks to Disaster Resilience: Bonding and Bridging Strategy in Hierarchical or Horizontal Collaboration Networks. Quality \& Quantity, 49, 1465-1483. https://doi.org/10.1007/s11135-014-0092-x

[17] Kantur, D. and Isery-Say, A. (2015) Measuring Organizational Resilience: A Scale Development. Journal of Business, Economics and Finance, 4, 456-472. https://doi.org/10.17261/Pressacademia.2015313066

[18] Powley, E.H. (2009) Reclaiming Resilience and Safety: Resilience Activation in the Critical Period of Crisis. Human Relations, 62, 1289-1326. https://doi.org/10.1177/0018726709334881

[19] Husserl, E. (1968) The Crisis of European Sciences and Transcendental Phenomenology. Il Saggiatore, Milano, 33-36.

[20] Holt, C. and David, M.H. (1966) The Concept of Job Vacancies in a Dynamic Theory of the Labor Market. In: The Measurement and Interpretation of Job Vacancies, NBR Other Conference Series, 5, Columbia University Press, New York, 73-110.

[21] Nickell, S.J. (1986) Dynamic Models of Labour Demand. In: Ashenfelter, O.C. and Layard, R., Eds., Handbook of Labor Economics, Vol. 1, North Holland, Amsterdam, 473-522.

[22] Cogley, T. and Nason, J.M. (1995) Output Dynamics in Real-Business-Cycle Models. The American Economic Review, 85, 495-511.

[23] European Commission (2013) European Business Cycle Indicator, 2. http://ec.europa.eu/economy_finance/publications/cycle.../2_en.pdf

[24] ISTAT (Istituto Nazionale di Statistica) (2008) Rapporto annuale. La situazione del Paese. Annual Report, The Country's Situation, Roma, 48-49. http://www.istat.it

[25] Pissarides, C.A. (1985) Short-Run Equilibrium Dynamics of Unemployement, Vacancies, and Real Wages. The American Economic Review, 75, 676-690.

[26] Burnside, C., Eichenbaum, M. and Rebelo, S.T. (1993) Labour Hording of the 
Business Cycle. Journal of Political Economy, 101, 245-273.

https://doi.org/10.1086/261875

[27] CNEL (Consiglio Nazionale dell'Economia e del Lavoro) (2014) Labor Market Report 2013-2014. 40-48. http://www.cnel.it

[28] EUROSTAT (2002) Methodology of the Short-Term Business Statistics. Office for Official Publications of the European Communities, Luxembourg, 45.

[29] EUROSTAT Statistics Explained (2017) Glossary: Lagging Indicator. http://ec.europa.eu/eurostat/statistics-explained

[30] EUROSTAT (2017) Handbook on Cyclical Composite Indicators. For Business Cycle Analysis. Publications Office of the European Union, Luxembourg, 76-77.

[31] Remon-Tiedrez, I. (2005) From Opinions to Facts... Links between Short-Term Business Statistics and Business and Consumer Opinion Surveys. Focus in Statistics, 15, European Communities (EUROSTAT), 7. http://www.ec.europa.eu/eurostat

[32] Rodano, R. (2015) The Italian Labour Market before and after the Jobs Act. Università di Roma "La Sapienza", 1-32. www.pietroichino.it/wp-content/uploads/2015/05/Rodano-sul-Jobs-Act.pdf

[33] EXCELSIOR (2015) La domanda di professioni e di formazione delle imprese italiane (Professions and Training in Italian Companies). Unioncamere-Ministero del Lavoro, Sistema Informativo Excelsior, Roma, 51-53.

http://excelsior.unioncamere.net

[34] Grandori, A. (1984) Organization Theory. Giuffrè, Milano, 22.

[35] Turati, C. (1989) Flexibility and Segmentation of Work Relationships. In: Nacamulli, R.C.D., Trade Union Relationships and Managerial Initiative, Franco Angeli, Milano, 423-477.

[36] Griffiths, A. and Winn, M.I. (2005) Slack and Sustainability. The Annual Meetings of the Academy of Management, Hawaii, August 2005.

[37] Ferrara, M. (2008) Flexible Work Management. Giappichelli, Torino, 159-175.

[38] CIPD (Chartered Institute of Personnel and Development) (2009) Employee Outlook. Working Life in a Recession. Quarterly Survey Report, 1-29.

[39] Robertson, I.T. and Cooper, C.L. (2013) Resilience. Stress and Health, 29, 175-176. https://doi.org/10.1002/smi.2512

[40] Robertson, I.T., Cooper, C.L., Sarkar, M. and Curran, T. (2015) Resilience Training in the Workplace from 2003-2014: A Systematic Review. Journal of Occupational and Organizational Psychology, 88, 533-562. https://doi.org/10.1111/joop.12120

[41] Hammer, M. and Champy, J. (1993) Reegineering the Corporation. Harper Business, New York.

[42] Moskal, B.S. (1996) Reengineering without Downsizing. Industry Week, 19 February, 23-28.

[43] Grandori, A. (1996) Organizational Research Design. In: Costa, G. and Nacamulli, R.C.D., Eds., Manual of Organization Theory, 5: Methods and Techniques of Analysis and Intervention, Utet, Torino, 3-47. 